\title{
Learner Autonomy in Higher Education
}

\author{
Towards a validation of the PRO-SDLS scale to Portuguese engineering students
}

\author{
M. Duarte \\ ISEP-IPP Oporto's Polytechnic Institute / CIDEM \\ FPCE-UP Oporto's University / CIIE \\ Porto, Portugal \\ mic@isep.ipp.pt
}

\begin{abstract}
Learner autonomy and self-direction in learning in higher education has become increasingly important as the focus changes from the teacher to the learner. Lifelong learning and the ability to continuously learn are only possible if students have more control of their own learning. This study is a first step towards an adaptation and validation of a Portuguese version of the Personal Responsibility Orientation to Self-Direction in Learning Scale (PRO-SDLS) to undergraduate engineering students. Using factor and reliability analysis, 12 items of the translated scale showed strong validity and reliability. The findings indicate that the PRO-SDLS can be used with engineering undergraduate students. More data collection and confirmatory analysis is suggested.
\end{abstract}

Keywords-learner autonomy; higher education; measurement scale; self-direction; engineering students

\section{INTRODUCTION}

In the European Higher Education Area, lifelong learning has been recognized as an essential element, being critically important given the rapid pace of change of society [1]. This is particularly true in areas such as engineering and technology where new fields are constantly emerging [2]: what an engineer will need to know several years after graduating will not have been learned in school. So, in engineering, the education that succeeds will be the one that facilitates lifelong learning [3].

But lifelong learning means the ability to evaluate one's own learning needs and ways to continuously learn and improve, because "no learner can be effective in more than a very limited area if he or she cannot make decisions for themselves about what they should be learning and how they should be learning it" [4]. That's why Boud [4] argues that is not likely that students who are dependent on their teachers are going to be as effective in the world of learning or subsequent employment as those who have developed strategies which enable them to find and use their own resources for learning, emphasizing the importance of learner autonomy as a key element in higher education. Also, learner autonomy and self-direction in learning has been found to be related with better academic achievement.
The first definition of learner autonomy is attributed to Holec in 1979 [5] as being "Autonomy is the ability to take charge of one's own learning". Other definitions include "The ability to control one's learning" [6] and "Learner's ability and willingness to make choices independently" [7].

For Holec [5] learner autonomy is acquired. An individual with this ability may or may not use it. Learners must be willing to do so, but they also need the opportunity to do so. The learner that has this ability and makes full use of it is involved in self-directed learning. According to Holec [5] learner's autonomy is an individual capacity and self-directed learning describes the way in which an autonomous learner is involved in the teaching-learning transaction.

In spite of the importance of learner autonomy for lifelong learning, and the need to engineers continuously update their knowledge and skills, the majority of the published material and research on learner autonomy is related with university courses from humanities and social sciences, and not with engineering and technology [8] and these qualities are typically less emphasized in engineering education itself [9]. Also, as Chen and Lord [1] point out, given the importance of learner autonomy and lifelong learning, there are surprisingly few instruments to measure it in higher education.

That is why this study aim is the adaptation and validation of the PRO-SDLS scale [10] to Portuguese undergraduate engineering students, which measures self-directedness in learning based on an operationalization of the personal responsibility orientation (PRO) model of self-direction in learning. The procedure and data presented here refers to the pilot study, meaning that additional work will be done.

\section{INSTRUMENT: PRO-SDLS SCALE}

In 2011, Stockdale and Brockett [10] developed a reliable and valid instrument to measure self-directedness in learning among college students based on an operationalization of the personal responsibility orientation (PRO) model of selfdirection in learning. They felt that, in spite of the existence of several other scales, none of them were recent and did not address the specificity of higher education students.

The personal responsibility orientation (PRO) model of self-direction in learning is a conceptualization of selfdirection by Brockett and Hiemstra [11] that "provides a 
definitional foundation for understanding and recognizing differences and similarities in self-directed learning as a teaching and learning transaction external to the individual and learner self-direction as a personal orientation internal to the individual. Together they predispose on toward personal empowerment and accepting responsibility for such learning".

The authors [11] define the self-directed learning component as a "process in which a learner assumes primary responsibility for planning, implementing, and evaluating the learning process". In this process, the focus are the external factors and characteristics of the teaching-learning transaction, in which teachers play a facilitating role.

That's why the scale items for this component "will reflect agreement with actions that demonstrate proactively assuming control a initiative for planning, implementing and evaluating the learning process; items that relate to exhibiting control of the learning situation compose one factor, and items that relate to demonstrating initiative compose a second factor" [10].

As for the learner self-direction component, Brockett and Hiemstra [11] define it as "an individual beliefs and attitudes that predispose one toward taking primary responsibility for their learning (...) a learner's desire or preference for assuming responsibility for learning". This component also included learner's self-efficacy in self-directed activities, as defined by Bandura [12] as "beliefs in one's capacities to organize and execute the courses of action required to produce given attainments".

So, the learner self-direction component of the scale "was conceptualized as behaviors relating to learner autonomous motivation and perceived self-efficacy for self-direction in learning" [10], including items that relate to motivation and items that relate to self-efficacy.

The PRO-SDLS scale is based on a five-point Likert type format that was found suitable to "best reflect student's degree of agreement or disagreement with statements pertaining to self-perceptions of their actions and beliefs in self-directed learning opportunities" [10]. The scale contains 25 items and those that were considered negative with respect to the construct were reverse scored.

The scale has two major components: teaching-learning transaction (TLT) and the learner characteristic (LC), which includes 12 items and 13 items, respectively. In the TLT component, items $2,9,10,15,17$ and 25 refer to initiative, while items $4,5,6,13,19$ and 23 refer to control. In the LC component, items $3,8,11,14,16,18$ and 20 refer to motivation and items $1,7,12,21,22$ and 24 refer to selfefficacy.

For the development of PRO_SDLS scale, convenience sampling was used. A total of 518 undergraduate (educational psychology course) and graduate (adult learning course) college students, voluntarily participated during a three semester period. According to Stockdale and Brockett [10], "the investigation comprised three research studies, the first two of which served as pilots for this main study (...). A confirmatory analysis was performed with the 25 items to determine if the model conformed to the data. Data from the final scale were then used to examine issues of reliability".
The authors [10] also provided evidence of scale validity, specific criteria validity, congruent validity and convergent validity. "Incremental validity statistics were also used to demonstrate that the PRO-SDLS scale added significant unique variance to the prediction of self-direction above and beyond scores from the traditional scales" [10].

\section{METHOD}

\section{A. Participants}

The participants were undergraduate higher education Portuguese students of two engineering courses (Bologna first cycle with three years) of Oporto Polytechnic Institute Engineering School, which had 5294 undergraduate students (according to the 2011 School report). Convenience sampling was adopted.

A total of 162 students (154 men and 8 women) agreed to participate in the study. The students age ranged from 18 to 57 years $(M=22.36, S D=6.43)$. Most were first year students $(47.5 \%) ; 37.7 \%$ were second year students and $14.8 \%$ were in the third year. First year students were younger $(M=20.06$, $\mathrm{SD}=3.46)$ than second year $(\mathrm{M}=22.87, \mathrm{SD}=6.14)$ and third year students $(\mathrm{M}=28.42, \mathrm{SD}=9.73)$.

Of the 162 students, 97 students (59.9\%) attended classes during the day, while $65(40.1 \%)$ did it at night because they work during the day. Students attending classes during the day were younger $(M=20.27, S D=3.62$; range from 18 to 41$)$ than those attending it at night $(\mathrm{M}=25.48, \mathrm{SD}=8.23$; range from 18 to 57$)$.

\section{B. Procedure}

The adaptation of PRO-SDLS scale began by contacting its author, who was kind enough to send it by email and give permission to its use and translation into Portuguese. A first translation was made by the investigator and reviewed by three experts (one in self-direction, another in educational sciences and another one in language learning). In order to check for ambiguous meanings in the test items, a group of twelve engineering students were asked to answer the translated questionnaire. Their suggestions were taken into consideration.

Students were approached during classes (with the teachers' permission and collaboration) in October of 2012 and asked whether they would complete the paper-based questionnaire. Students completing the paper questionnaire were told by the investigator what the purpose of the study was and that the data collection was anonymous, and that returning the completed questionnaire to the researcher was taken as providing informed consent. If they did not want to participate in the study they simply returned a blank questionnaire. Approval for the study was obtained from the President of the Engineering School.

After data collection, the validity and reliability were tested. Exploratory factor analysis (principal components analysis extraction method; varimax rotation) was used to test the validity of the scale. The indicator of the scale's reliability 
was internal consistency, and Cronbach's alpha was performed. Pearson's product-moment correlation was used to confirm the relationship between the factors.

\section{RESULTS}

The 25 items of the Personal Responsibility Orientation to Self-Direction in Learning Scale were subjected to exploratory factor analysis (principal components analysis extraction method; varimax rotation) in SPSS 19.0.

In the initial run, seven factors with eigenvalues greater than one were identified. All items loaded substantially in one or more factors, using the criterion of a factor loading less than 0.45 because the sample size was under 200. Two items (item 8 and item 9) loaded almost the same and under 0.50 in two factors and were dropped.

In the next run, one item (item 13) did not load in any factor and was dropped.

In the next two runs, some factors had only two factors and so these items (item 16, item 18, item 12 and item 5) were dropped.

In the fifth run five factors with eigenvalues greater than one were identified. At this point three items (item 25, item 1 and item 7) were dropped because they loaded in a factor that was different from the one expected, according to the PROSDLS theoretical construct two items. The same happened in the sixth run with item 6. In this run four factors with eigenvalues greater than one were identified.

In the last run two additional items (item 14 and item 2) were dropped in order to increase the variance explained by the factors. The four factors identified accounted for $60.66 \%$ of the variance and included 12 items $(3,4,10,11,15,17,19$, $20,21,22,23,24)$, which was three items per factor. Factor one (control; items 4, 19, 23), factor two (initiative; items 10, 15,17 ), factor three (self-efficacy; item 21, 22, 24) and factor four (motivation; item 3, 11, 20) explained $12.53 \%, 14.50 \%$, $16.28 \%$ and $17.35 \%$ of the variance, respectively. Factors' loadings are included in table I. Communalities ranged from 0.441 to 0.815 (see table II).

The sample size was adequate with a Kaiser-Meyer-Oklin value of 0.778 and Bartlett's test of sphericity (Quisquare $=422.714 ; \quad \mathrm{df}=66$ ) was statistically significant as required. There were $47 \%$ of nonredundant residuals with absolute values less than 0.05 .

The alpha levels were satisfactory (see table III), being 0.781 for the total scale, 0.574 for factor one (control; items 4 , 19, 23), 0.562 for factor two (initiative; items 10, 15, 17), 0.685 for factor three (self-efficacy; item $21,22,24$ ) and 0.648 for factor four (motivation; item 3, 11, 20).
TABLE I. RESULTS OF THE FACTOR ANALISYS (FACTORS' LOADINGS)

\begin{tabular}{|c|c|c|c|c|}
\hline \multirow{2}{*}{$\begin{array}{l}\text { Scale } \\
\text { items }\end{array}$} & \multicolumn{4}{|c|}{ Factor loading } \\
\hline & Factor 1 & Factor 2 & Factor 3 & Factor 4 \\
\hline 04 & 0.896 & & & \\
\hline 19 & 0.535 & & & \\
\hline 23 & 0.474 & & & \\
\hline 10 & & 0.582 & & \\
\hline 15 & & 0.775 & & \\
\hline 17 & & 0.723 & & \\
\hline 21 & & & 0.530 & \\
\hline 22 & & & 0.761 & \\
\hline 24 & & & 0.788 & \\
\hline 03 & & & & 0.737 \\
\hline 11 & & & & 0.589 \\
\hline 20 & & & & 0.771 \\
\hline
\end{tabular}

TABLE II. RESULTS OF THE FACTOR ANALISYS (COMMUNALITIES)

\begin{tabular}{|c|c|}
\hline Scale items & Communality \\
\hline 04 & 0.815 \\
\hline 19 & 0.529 \\
\hline 23 & 0.559 \\
\hline 10 & 0.482 \\
\hline 15 & 0.620 \\
\hline 17 & 0.686 \\
\hline 21 & 0.537 \\
\hline 22 & 0.664 \\
\hline 24 & 0.664 \\
\hline 03 & 0.588 \\
\hline 11 & 0.441 \\
\hline 20 & 0.696 \\
\hline
\end{tabular}

TABLE III. RESULTS OF THE SCALE'S RELIABILITY

\begin{tabular}{|c|c|}
\hline Factors & Cronbach's alpha \\
\hline Control & 0.574 \\
\hline Initiative & 0.562 \\
\hline Self-efficacy & 0.685 \\
\hline Motivation & 0.648 \\
\hline Total (PRO-SDLS) & 0.781 \\
\hline
\end{tabular}


A Pearson product-moment correlation was computed to examine the associations between the factors (see table IV). All correlations are significant at the 0.01 level (2-tailed). Factors correlations with learner autonomy (PRO-SDLS total) are strong. Factors correlations among themselves are moderate.

TABLE IV. RESULTS OF THE CORRELATION ANALISYS

\begin{tabular}{|c|c|c|c|c|}
\hline Factors & Control & Initiative & Self-efficacy & Motivation \\
\hline Control & 1 & 0.391 & 0.412 & 0.388 \\
\hline Initiative & 0.391 & 1 & 0.222 & 0.246 \\
\hline Self-efficacy & 0.412 & 0.222 & 1 & 0.464 \\
\hline Motivation & 0.388 & 0.246 & 0.464 & 1 \\
\hline Total (PRO-SDLS) & 0.749 & 0.629 & 0.745 & 0.747 \\
\hline
\end{tabular}

Table $\mathrm{V}$ includes descriptive statistics such as means, standard deviations and standard errors for PRO-SDLS scale Portuguese version total and factors.

TABLE V. PRO-SDLS SCALE DESCRIPTIVE STATISTICS

\begin{tabular}{|c|c|c|c|c|}
\hline Factors & $\mathrm{N}$ & $\mathrm{M}$ & Std. Deviation & Std. Error \\
\hline Control & 162 & 10.06 & 1.877 & 0.147 \\
\hline Initiative & 162 & 9.05 & 1.897 & 0.149 \\
\hline Self-efficacy & 162 & 10.83 & 2.111 & 0.166 \\
\hline Motivation & 162 & 10.51 & 2.124 & 0.167 \\
\hline Total (PRO-SDLS) & 162 & 40.44 & 5.759 & 0.452 \\
\hline
\end{tabular}

\section{DISCUSSION}

The 12-item scale that has been adapted and validated is psychometrically sound, demonstrating the same structure of the original PRO-SDLS by Stockdale and Brockett [10].

The fact that it wasn't possible to validate all 25 items was expected because, as stated by Stockdale and Brockett [10] "an important direction for future research is the need to continue developing instruments designed for specific settings. The conceptualization of the PRO-SDLS could serve as an underlying framework for such instruments; however, the language and focus of each instrument would be aimed at a different target audience", meaning that not all items might be adequate for all cultures and students.

As mentioned earlier this is a pilot study, so more data will be collected and confirmatory analysis will be performed to confirm exploratory analysis result's and model adjustment to the data. The possibility of adding additional items to Portuguese validated scale in order to make it more specific to engineering students will be considered. Misconceptions about learner autonomy will also be investigated with a series of interviews and focus groups.

\section{Acknowledgment}

Doctor Susan Stockdale for sharing the English version of PRO-SDLS scale and allowing its adaption for Portuguese.

\section{References}

[1] Chen, J. C., \& Lord, S. M. "Engineering Students' Development as Lifelong Learners". In 120th ASEE Annual Conference and Exposition Proceedings. Atlanta:ASEE, 2013.

[2] Dutta, D., Patil, L., \& Porter Jr, J. B. "Lifelong Learning Imperative in Engineering: Sustaining American Competitiveness in the 21st Century". National Academies Press, 2012.

[3] Rugarcia, A., Felder, R. M., Woods, D. R., \& Stice, J. E. "The future of engineering education I. A vision for a new century". Chemical Engineering Education, 34(1), 16-25, 2000.

[4] D. Boud, "Developing student autonomy in learning", London: Kogan Page, 1988.

[5] H. Holec, "Autonomie et apprentissages des langues étrangères", Strasburgo: Conseil de L'Europe, 1979.

[6] P. Benson, "Teaching and researching autonomy in language learning", Harlow: Longman/Pearson Education, 2001.

[7] D. Little, "Learner Autonomy 1: Definitions, Issues and Problems", Dublin: Authentik, 1991.

[8] Vemury, C., \& Devlin, M. "Personalised Approach to Learner Autonomy". In Proceedings of the 20th Annual Conference for the Australasian Association for Engineering Education (pp 150-157). Adelaide: AAEE, 2009.

[9] Bramhall, M, Radley K, Metcalf, J, 'Users as producers: students using video to develop learner autonomy', presented at Engineering Education 2008 Innovation, Good Practice and Research in Engineering Education, Loughborough University, 2008.

[10] S. L. Stockdale and R. G. Brockett, "Development of the PRO-SDLS: A Measure of Self-Direction in Learning Based on the Personal Responsibility Orientation Model”, Adult Education Quarterly, 61(2), pp.161-180, 2011.

[11] R. G. Brockett and R. Hiemstra, "Self-direction in learning: Perspectives on theory, research, and practice", London and New York: Routledge, 1991.

[12] A. Bandura, "Self-efficacy: the exercise of control", New York: W. H. Freeman and Company, 1997. 